\title{
Extraosseous Ewing's Sarcoma of the Maxillary Sinus: A Very Rare Entity
}

\begin{abstract}
Ewing's sarcoma is rare sarcoma of bone and soft tissue that uncommonly involve the head and neck in both bone and soft tissue locations. The term Ewing's sarcoma family of tumors comprises both Ewing's sarcoma and peripheral neuroectodermal tumor. It was in 1975, Angervall and Enzinger described the Ewing's sarcoma arising in soft tissues (extraskeletal). The principal sites of extraskeletal Ewing's sarcoma are the paravertebral region and chest wall, generally in close association with vertebrae or the ribs. These tumors may also arise in the soft tissues of the lower extremities and rarely in the pelvic region and hip regions. Superficially located cases do occur but are rare. Here, we present a case of Ewing's sarcoma involving the maxillary sinus region. A 12-year-old boy reported to our department with a swelling on the right side of middle third of the face for 15 days. Intraorally, there was only obliteration of the labial vestibule. On histopathological examination, a provisional diagnosis of malignant round cell tumor was given. Immunohistochemistry with a panel of markers was done to come to a definitive diagnosis. CD99 positivity confirmed the diagnosis of Ewing's sarcoma.
\end{abstract}

Keywords: Ewing's sarcoma, extraskeletal, maxillary region

\section{Introduction}

Ewing's sarcoma is a highly malignant round cell tumor affecting the bone. It is classified under small round cell tumors. It was first described by James Ewing in 1921. He called it a "diffuse endothelioma of bone" suggesting an endothelial derivation. ${ }^{[1]}$ Later, there was much debate regarding the origin of this tumor. Finally, it was thought to be arising from the cells of the neural crest. Reports also strengthened this by identifying a cytogenetic abnormality of chromosomal translocation between $\mathrm{t}(11 ; 22)$ (q 24, q12) in $90 \%-95 \%$ of Ewing's Sarcomas. ${ }^{[1,2]}$

The Ewing's sarcoma is a constituent of the Ewing's sarcoma family of tumors (ESFT), which also include peripheral primitive neuroectodermal tumor (PNET), neuroepithelioma, and Askin tumor of the chest wall. ${ }^{[2,3]}$ All these tumors share the common chromosomal translocation. They have many overlapping features suggesting a common histogenesis.

Ewing's sarcoma represents about 4\%-\% of all bone tumors ${ }^{[4]}$ and it is only second to osteosarcoma in its occurrence. It mainly affects the paravertebral region and the

This is an open access journal, and articles are distributed under the terms of the Creative Commons Attribution-Non Commercial-ShareAlike 4.0 License, which allows others to remix, tweak, and build upon the work non-commercially, as long as appropriate credit is given and the new creations are licensed under the identical terms.

For reprints contact: reprints@medknow.com extremities. Less than $5 \%$ of ES arise in the maxillofacial region. It is usually seen in the first two decades of life. ${ }^{[5]}$ A very rare subset is the extraosseous variety of Ewing's Sarcoma. It was described by Franz Enzinger and Sharon W. Weiss in $1975{ }^{[1]}$ It arises in the soft tissues and has similar histologic, immunohistochemical, and molecular findings with Ewing's sarcoma arising intraosseously. ${ }^{[6]}$

Extraosseous Ewing's sarcoma (EES) is very rare and cases have been reported from larynx, pterygomandibular space, fingers, and chest wall. We hereby report a case of a 15-year-old boy with EES arising from the maxillary sinus.

\section{Case Report}

A 12-year-old boy was admitted to our college with a chief complaint of swelling of the right cheek region for 12 days. The swelling was noted 2 weeks back, with a faster increase in size. The swelling was not associated with any pain.

The medical history of the patient did not reveal any significant information. There was no history of trauma or caries. The extraoral clinical examination showed a $2 \mathrm{~cm} \times 3 \mathrm{~cm}$ swelling extending $1 \mathrm{~cm}$ from the right ala of the nose to $2 \mathrm{~cm}$ in front

How to cite this article: Prakash AR, Simha Reddy AV, Killampalli LK, Rajinikanth M. Extraosseous Ewing's sarcoma of the maxillary sinus: A very rare entity. Indian J Med Paediatr Oncol 2018;39:380-4.

\section{A Ravi Prakash, A Vikram Simha Reddy, Lakshmi Keerthana Killampalli, M Rajinikanth}

Department of Oral Pathology and Microbiology, G. Pulla Reddy Dental College and

Hospital, Kurnool,

Andhra Pradesh, India

Address for correspondence:

Dr. Lakshmi Keerthana

Killampalli,

Department of Oral Pathology and Microbiology, G. Pulla Reddy Dental College and Hospital, Kurnool,

Andhra Pradesh, India.

E-mail: kheer9@gmail.com

Access this article online

Website: www.ijmpo.org

DOI: 10.4103/ijmpo.ijmpo_11_16

Quick Response Code:
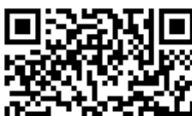

revpest:

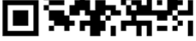


of the ear anteroposteriorly, and from the right infraorbital area to the line extending from the corner of the mouth superoinferiorly [Figure 1]. Intraoral examination revealed obliteration of the right labial vestibule [Figure 2].

Computed tomography scan (CT scan) of the head and neck region was done. The axial sections of the CT scan showed a soft-tissue density or a radiopaque mass in the right maxillary sinus occupying the entire sinus. The radiopacity extended from the axial sections of the mesial surface of right lateral incisor to the distal surface of the first maxillary molar anterioposteriorly. Superoinferiorly from the floor of the orbit to the floor of the sinus, there is an expansion of the sinus cavity, resulting in the expansion of the buccal cortical plate of the maxilla. The radiopacity was uniformly dense and did not match the radiopacity of the bone, suggesting there are no notable calcifications in the mass. All other paranasal sinuses are normal. The nasal turbinates are also spared [Figures 3 and 4].

An incisional biopsy was taken from the right labial vestibule and submitted for histopathological examination.

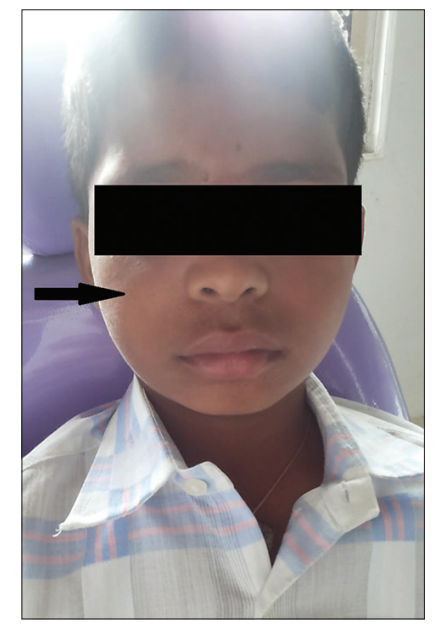

Figure 1: Extraoral picture of the patient shows a diffuse swelling on the right side of the face

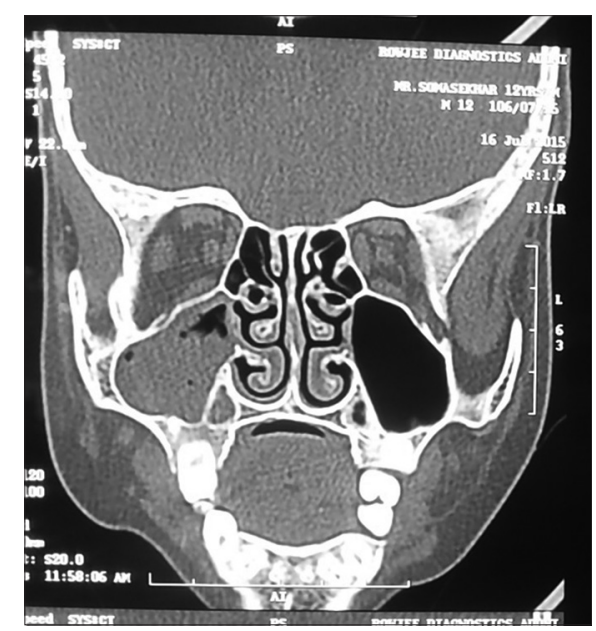

Figure 3: Computed tomography scan shows the increased radiopacity in the right maxillary sinus of the face. The other paranasal sinuses are spared
The findings showed connective tissue stroma with a dense, homogenous proliferation of small round to oval blue cells. These cells were arranged in sheets and strands separated by connective tissue septa. The cells showed a round to oval basophilic, hyperchromatic nucleus surrounded by a scanty rim of cytoplasm which was inconspicuous [Figure 5].

The histopathological findings led us to a provisional diagnosis of small round cell tumor which presented us with a myriad of tumors. They included Ewing's Sarcoma, lymphoma, small cell osteosarcoma, rhabdomyosarcoma, etc., therefore, a panel of immunohistochemical markers was used to come to a final diagnosis. The panel of markers included CD99, Mib-1, cytokeratin, leukocyte common antigen (LCA), and chromogranin.

The cells showed strong positivity for CD99 [Figure 6], the additional stains that were added to detect the epithelial origin of the cells (Cytokeratin) [Figure 7], leukocytic origin (LCA) [Figure 8] to rule out lymphomas were negative. Chromogranin which was added to identify the neuroendocrine differentiation was not contributory [Figure 9]. Mib-1 which is used to detect the proliferative potential was positive at focal areas. Thus, all the above

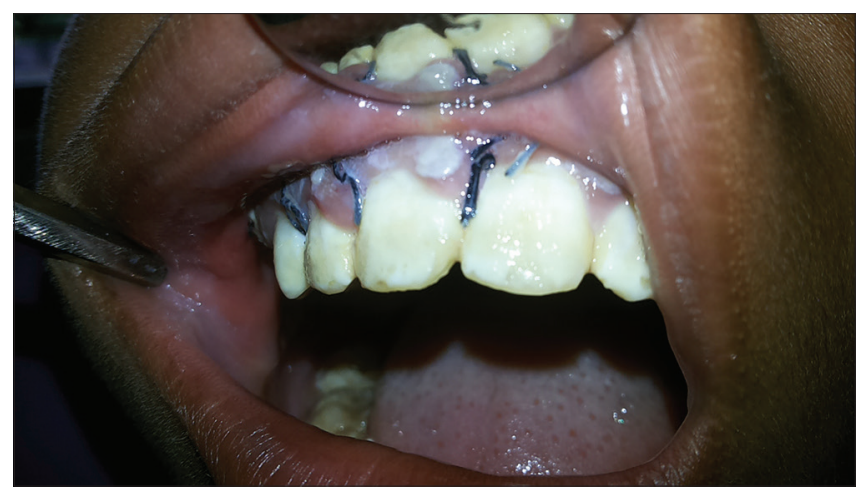

Figure 2: Intraoral examination shows obliteration of the right labial

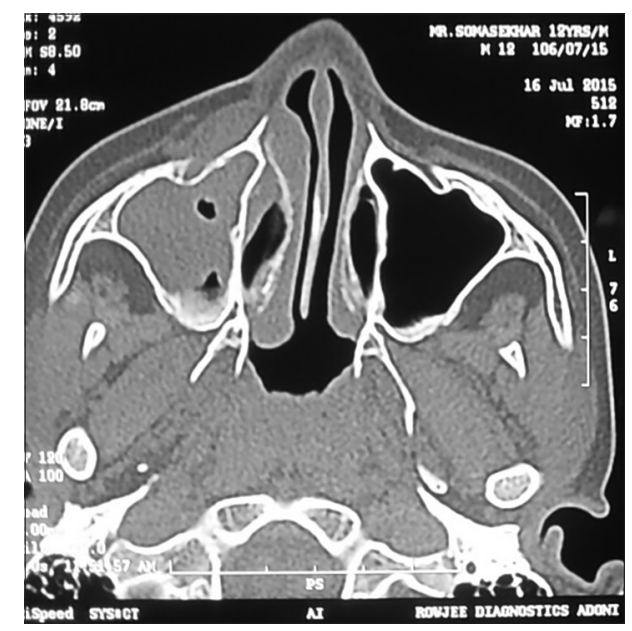

Figure 4: The computed tomography scan view of the skull shows the increased radiopacity in the right maxillary sinus. The nasal turbinates are all spared 


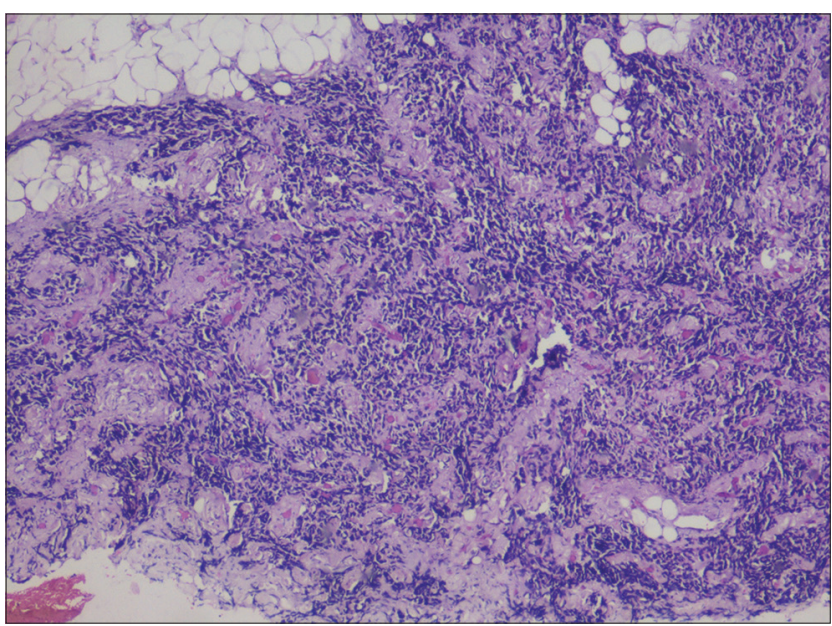

Figure 5: The $\mathrm{H}$ and $\mathrm{E}$ picture shows sheets of densely arranged small round cells with hyperchromatic nuclei invading the adipose tissue (magnification, $\times 4$ )

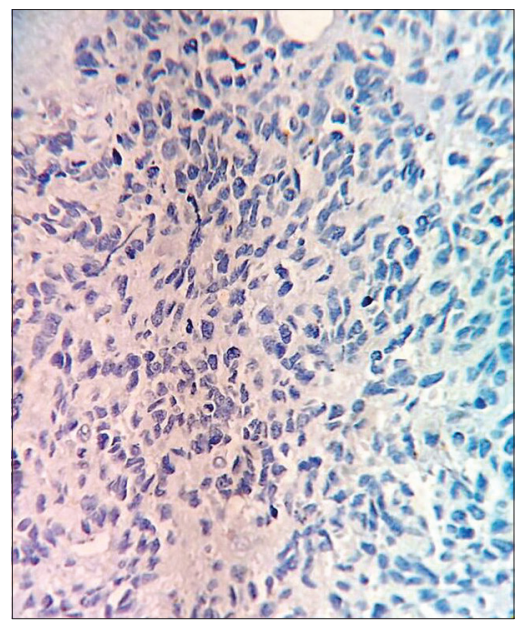

Figure 7: Cytokeratin staining showed negative results for the tumor cells

mentioned findings, inclined the diagnosis towards extraosseous Ewing's Sarcoma.

The patient was then treated in a chemosurgical approach. Initially, the patient was surgically excised of the tumor and kept on chemotherapeutic drugs. The drugs included adriamycin, vincristine, and cyclophosphamide. The surgery was performed in September 2015, and thankfully no signs of recurrence were noted in the patient till date.

\section{Discussion}

Ewing's sarcoma and its related tumors have always been a topic of ambiguity. But with the advent of immunohistochemical, molecular, and cytogenetic studies, a great deal of progress has been made in the understanding of these tumors. ESFT is a group of related tumors which includes the classic Ewing's sarcoma of the bone, PNET, extraosseous Ewing's sarcoma (EES), malignant small cell tumor of the thoracopulmonary region (Askin's tumor). ${ }^{[7]}$

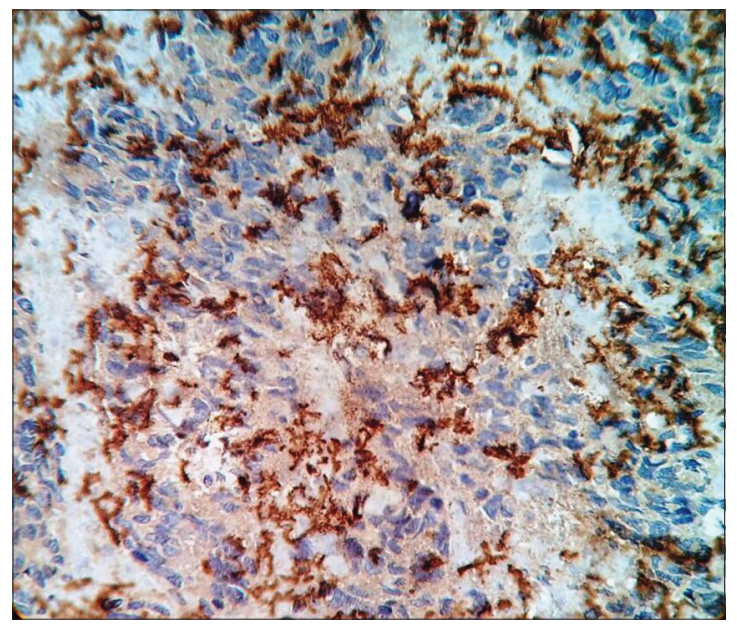

Figure 6: CD99 positivity of the tumor cells

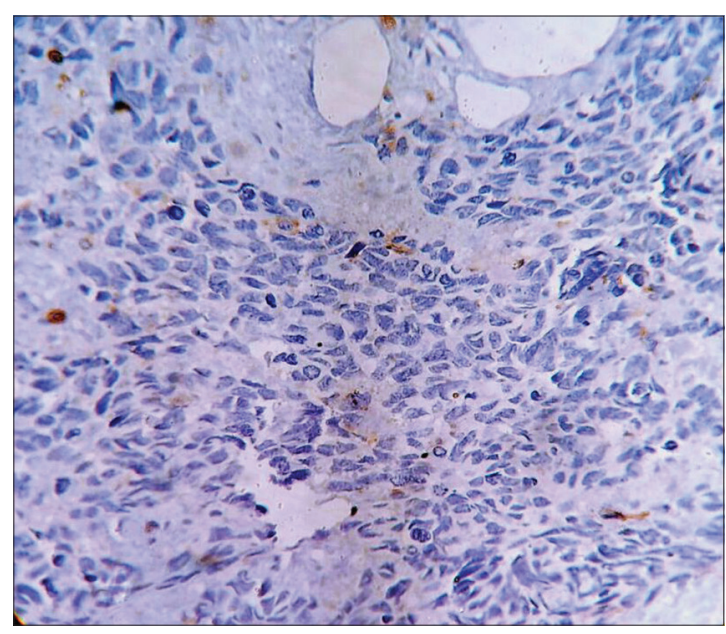

Figure 8: Leukocyte common antigen also stained negative

Members of the Ewing sarcoma/PNET family of tumors are characterized by rearrangements involving the EWS gene on chromosome 22q12 and fusion partners from the ETS oncogene family, most frequently FLI1 on chromosome $11 \mathrm{q} 24(85 \%)$, or ERG on chromosome 21q22 (10\%). Ninety-five percent of ESFT have fusion of the central exons of the EWSR1 gene (Ewing's sarcoma Breakpoint Region 1) to the central exons of an ETS gene family member and fusion occurs between the $\mathrm{NH} 2$ end of the EWS gene and the- $\mathrm{COOH}$ end of the ETS gene family partner. ${ }^{[8,9]}$

EES was first put forward by Tefft et al. in 1969 and later described by Angerwall et al. in 1975. EES is a rare variety which can occur in any soft tissue. It has been reported in the paravertebral spaces, retroperitoneum, pelvis, larynx, nasal cavity, ${ }^{[10]}$ etc., To the best of our knowledge, there is one case reported in the literature about EES arising exclusively in the maxillary sinus and this is the second case.

Ewing's Sarcoma (ES) is exclusive in the bone. PNET has been termed as the extraskeletal variant of ES. EES 


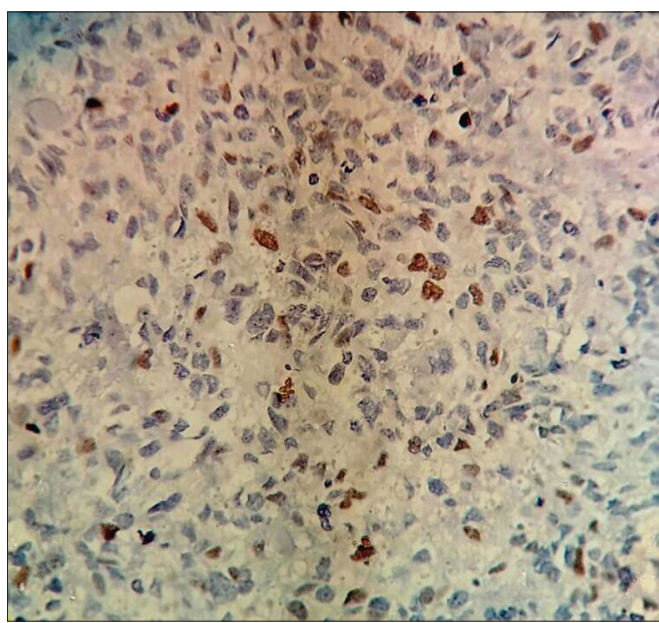

Figure 9: Chromogranin staining was not contributory

is also similar to PNET as arising in the soft tissues but does not have the typical neural differentiation which forms the differentiating factor between them. ${ }^{[1]}$ The histopathologic features of EES includes sheets of small round cells (included under Small Round Cell Tumors) with a uniform hyperchromatic nucleus and scanty cytoplasm. A variant termed as Atypical Ewing's sarcoma is seen wherein the monomorphic round cells are replaced by atypical-shaped cells with a hyperchromatic nucleus and scanty cytoplasm The clinical features of atypical Ewing's sarcoma resemble lymphomas, carcinomas, and sarcomas but the molecular and immunohistochemical features are similar to that of ES. ${ }^{[12]}$

The histological features of monomorphic uniform small round to oval cells with a basophilic nucleus make its differentiation from other round cell tumors difficult. The tumors that should always be considered before giving a diagnosis of EES are lymphoma, rhabdomyosarcoma, PNET, small round cell tumor, and small cell osteosarcoma. Immunohistochemistry plays a major role in separating EES from other tumors. CD99 is a significant positive marker for the tumor cells in EES, however, it has been present in other soft tissue tumors also. Therefore, a panel of marks should be used to rule out other lesions and come to a diagnosis of EES. LCA (LCA) which is positive for lymphocytes was done to rule out lymphoma and it proved unsuccessful in our case. Chromogranin positive in PNET representing the neural differentiation was also negative. Cytokeratins representative of epithelial lineage also proved negative. Whereas Mib-1 or Ki67 proliferative marker showed $30 \%-40 \%$ positivity in the areas of hot spots emphasizing the high proliferative potential of the lesion. Therefore, the present case was diagnosed as EES arising in the maxillary sinus.

Radiographic features also play an important part to delineate the extent and size of the tumor. ES usually shows a "sun ray" lesion thought it is common in many other bone lesions. ${ }^{[13]} \mathrm{CT}$ and MRI also help to know the extent of the tumor in the soft tissues and help in the treatment planning. In the present case, CT scan was very helpful in diagnosing it, as an exclusive extraosseous lesion and also enumerated the tumor size, margins, and volume.

The prognosis of EES depends on various factors which include tumor site, size, gender, age, metastases, and previous history of cancer therapy and also the cytogenetics of the tumor. Females of a younger age group with tumor site in the distal extremities with no metastases present with a good prognosis. ${ }^{[14]}$ EWS of the head and neck region have a better prognosis. It has a fairly good survival rate of about $35 \%-70 \%$. The survival rate has been improved a lot lately due to the advent of combination treatment protocols including chemotherapy and surgery. Radiotherapy has also been utilized in elderly patients with EES and in areas where surgery is futile. The standard protocol though has been initial chemotherapy followed by surgery that is followed by postoperative chemotherapy. The treatment strategy does not change for any of the ESFTs. A presurgical chemotherapy is opined to have better prognostic effects. ${ }^{[14]}$ Chemotherapy with a combination of drugs including vincristine, chlorambucil, and Adriamycin is a well-used.

\section{Conclusion}

EES is a rare variant of ES which is rarely seen in the head and neck region. The clinical features mimics many soft tissue tumors of the oral cavity. It has a higher metastases rate to distant sites, making its identification and accurate diagnosis the key factors in the outcome of the disease. They are aggressive lesions which warrant early biopsy and diagnosis. Preoperative chemotherapy and long-term follow-up are highly essential as they mainly occur in a tender age group of children and young adolescents, to prevent physical and psychological stress.

\section{Declaration of patient consent}

The authors certify that they have obtained all appropriate patient consent forms. In the form the patient(s) has/have given his/her/their consent for his/her/their images and other clinical information to be reported in the journal. The patients understand that their names and initials will not be published and due efforts will be made to conceal their identity, but anonymity cannot be guaranteed.

\section{Financial support and sponsorship}

Nil.

\section{Conflicts of interest}

There are no conflicts of interest.

\section{References}

1. Enzinger F, Weiss SW. Soft Tissue Tumors, $5^{\text {th }}$ Edition. Elsevier, 2008.

2. Deshingkar S, Barpande S, Tupkari J. Ewing's sarcoma of 
zygoma. J Oral Maxillofac Pathol 2009;13:18-22.

3. Jayakumar S, Power D. Ewings sarcoma/PNET: A histopathological review. Internet J Orthop Surg 2006;3:1-9.

4. Nasser F, Al Khalil M, Al Homsi O, Bin Mujeen E. Ewing's sarcoma of the maxillary sinus. Egypt J Ear Nose Throat Allied Sci 2015; 16:177-80.

5. Mukherjee A, Ray JG, Bhattacharya S, Deb T. Ewing's sarcoma of mandible: A case report and review of Indian literature. Contemp Clin Dent 2012;3:494-8.

6. Li W, Huang JT, Chen XQ, Shi RH, Jiang L, Zhao YF. Extraosseous Ewing's sarcoma arising from the pterygomandibular space. Open J Stomatol 2011;1:114-20.

7. Gaona-Luviano P, Unda-Franco E, González-Jara L, Romero P, Medina-Franco H. Primitive neu-roectodermal tumor of the vagina. Gynecol Oncol 2003;91:456-568.

8. Kelleher FC, Thomas DM. Molecular pathogenesis and targeted therapeutics in Ewing sarcoma/primitive neuroectodermal tumours. Clin Sarcoma Res 2012;2:6.
9. Bielack SS, Paulussen M, Köhler G. A patient with two Ewing's sarcomas with distinct EWS fusion transcripts. N Engl J Med 2004;350:1364-5.

10. Rud NP, Reiman HM, Pritchard DJ, Frassica FJ, Smithson WA. Extraosseous Ewing's sarcoma. A study of 42 cases. Cancer 1989;64:1548-53.

11. Ng SH, Ko SF, Cheung YC, Wong HF, Jung SM. Extraskeletal Ewing's sarcoma of the parapharyngeal space. Br J Radiol 2004;77:1046-9.

12. Machado I, Noguera R, Mateos EA, Calabuig-Fariñas S, López FI, Martínez A, et al. The many faces of atypical Ewing's sarcoma. A true entity mimicking sarcomas, carcinomas and lymphomas. Virchows Arch 2011;458:281-90.

13. Lopes SL, Almeida SM, Costa AL, Zanardi VA, Cendes F. Imaging findings of Ewing's sarcoma in the mandible. J Oral Sci 2007;49:167-71.

14. Ewing Sarcoma Treatment-for Health Professionals. Website of National Cancer Institute. 